\title{
COMPETÊNCIAS TÉCNICAS E COMPORTAMENTAIS DOCENTES NA EDUCAÇÃOO A DISTÂNCIA: REFLEXÕES E APONTAMENTOS
}

TECHNICAL AND BEHAVIORAL SKILLS TEACHERS IN DISTANCE EDUCATION: REFLECTION AND NOTES

\section{Fernando Ramos Lengler}

Recebido em 12.03.2015. Aprovado em 23.05.2016

Avaliado pelo sistema double blind review

DOI: http://dx.doi.org/10.12712/rpca.v10i2.563

fernandolengler@gmail.com

Complexo de Ensino Superior de Santa Catarina (CESUSC), Florianópolis/SC, BRASIL

\section{Marcos Baptista Lopez Dalmau \\ dalmau@ufsc.br \\ Universidade Federal de Santa Catarina(UFSC) - Florianópolis/SC, BRASIL}

\section{Resumo}

Este artigo analisa o grau das competências necessárias para a atuação docente na modalidade educacional a distância e aponta quais podem ser aprimoradas para o seu exercício laboral, em uma instituição de ensino superior ofertante de cursos na modalidade. A pesquisa envolve a participação de atores envolvidos com a modalidade que possuem interação com os docentes atuantes. A pesquisa define-se como de natureza descritiva com caráter de estudo de caso. Os instrumentos de coleta são questionários com questões de múltipla escolha, documentos, observação direta e bibliografias. O método de investigação possui delineamento qualiquantitativo e as análises de dados foram realizadas abordando: análise interpretativa e análise estatística de dados. Os resultados indicam que os resultados apresentados podem ser potencializados com aprimoramentos dos docentes acerca das competências técnicas, relacionadas ao domínio pedagógico e domínio comunicativo, e das competências comportamentais, relacionadas ao domínio técnico e domínio pedagógico.

Palavras-chave: Educação a Distância. Competências Docentes. Competências Técnicas. Competências Comportamentais. Administração Universitária.

\begin{abstract}
This article analyzes the degree of skills required for teaching practice in educational mode the distance and points, which can be improved for their work exercise, in a higher education institution offered courses in mode. The research involves the participation of stakeholders involved with the sport to have interaction with the active teachers. Research is defined as descriptive with case study of character. collection instruments are questionnaires with multiple choice questions, documents, direct observation and bibliographies. The method of research has qualitative and quantitative design and data analyzes were conducted addressing: interpretative analysis and statistical data analysis. The results indicate that the results can be enhanced with improvements of teachers about the technical skills related to the pedagogical area and communicative area, and behavioral skills related technical field and educational domain.
\end{abstract}

.Keywords: Distance Education. Teachers Skills. Technical Skills. Behavioral Skills. University Administration. 


\section{Introdução}

Esta pesquisa é parte da dissertação intitulada "Competências Docentes na Educação a Distância: estudo de caso no Cursto de Tecnologia em Processos Gerenciais" defendida no Programa de Pós-Graduação em Administração Universitária da Universidade Federal de Santa Catarina (UFSC) em conjunto com aprimoramentos realizados pelos autores.

Com o advento, nas últimas décadas, das tecnologias da informação e da Educação a Distância (EaD) muitas reflexões sobre seu potencial e possibilidades são efetivadas. É sabido que a dinâmica de mercado atual impõe que as pessoas se atualizem e aprimorem seus conhecimentos continuamente e, por isso, ocorreu a necessidade de criação de uma forma inovadora que possa transmitir e trocar informações com agilidade e a qualquer tempo, além de possuir uma abrangência geográfica maior (LENGLER, 2014).

Entre as modalidades educacionais existentes, na educação presencial é onde acontece essencialmente a presença física dos atores que participam do processo de ensino e aprendizagem, e a modalidade de educação a distância (EaD) conta, basicamente, com o avanço das Tecnologias de Informação e Comunicação (TIC), com materiais de apoio e suporte de especialistas, além de possibilitar uma autonomia de estudo. Resumidamente, a diferenciação entre essas duas modalidades, presencial e a distância, remete ao distanciamento dos seus atores e a inclusão das tecnologias de apoio (LENGLER, 2014).

Moore e Kearsley (2013) salientam em sua obra que a $\mathrm{EaD}$ pode chegar a lugares onde a modalidade presencial não chegaria, por falta de investimentos ou estrutura. Klaes (2005) afirma que a modalidade $\mathrm{EaD}$ tem avançado geograficamente em todo o mundo e é a única forma capaz de conciliar a necessidade da educação superior com os problemas de mobilidade urbana, financeiros e de tempo, recursos cada vez mais escassos.

Segundo Barreto, Pinto e Martins (1999), a modalidade $\mathrm{EaD}$ apresenta vantagens que se caracterizam pela utilização de tecnologias, pelo atendimento de um público diversificado, pela superação da dificuldade geográfica, pela redução de custos, pela autonomia e ritmo de estudos e, essencialmente, pela democratização do acesso ao ensino.
O distanciamento físico dos discentes com a estrutura física educacional não impossibilita a existência de um ambiente de aprendizagem propriamente dito, muito pelo contrário, com a utilização das TIC's na educação, que propicie um ambiente virtual, surgem diversas vantagens, como: interação entre o computador e o discente; possibilidade de dar atenção individual; autonomia do discente com seu próprio ritmo de aprendizagem, assim como sua sequência; mais atratividade nos materiais de estudo estimulando e motivando a aprendizagem; possibilidade de avaliação dos discentes (NOTARE; BEHAR, 2009).

Acerca da relação dos docentes com discentes por intermédio das tecnologias de comunicação, com encontros virtuais, trocas de mensagens, feedbacks, entre outras, os autores Notare e Behar (2009) argumentam que existe sim uma disparidade por parte dos discentes no nível de integração e familiaridade com o meio virtual, já que isso depende muito do perfil, maturidade, autonomia, motivação e tempo do discente. Por isso, os autores destacam a importância dos docentes diversificarem as atividades propostas no Ambiente Virtual de Aprendizagem (AVA), para incentivar os discentes mais passivos, para que obtenham experiências positivas no ambiente virtual, e, assim, buscar uma comunicação que permitirá maiores interações, adaptações aos diferentes ritmos e liberdade de expressão.

Vergara (2007) ressalta a importância do relacionamento discente-docente para a construção do conhecimento e educação. Argumenta também que o relacionamento entre esses atores da $\mathrm{EaD}$ acontece constantemente, mas essa relação envolve os discentes, os docentes, os tutores e outros responsáveis nos processos educacionais a distância.

Belloni (2006) fomenta o debate sobre o papel do docente na $\mathrm{EaD}$, na qual este profissional assume, no processo de construção do conhecimento e educação, uma forma mais forte e necessária de parceiro do aluno, ou seja, o foco principal deste processo na $\mathrm{EaD}$ deixa de ser o ensino e passa a ser a aprendizagem de forma coletiva.

De acordo com Piaget e Greco (1974), a aprendizagem é o processo de aquisição de conhecimentos, habilidades ou atitudes e o ensino é um processo de transmissão de conhecimentos, habilidades ou atitudes. Segundo Moraes (2002, p.203): 
“em qualquer situação de aprendizagem, a interação entre os participantes é de extrema importância. É por meio das interações que se torna possível a troca de experiências, o estabelecimento de parcerias e a cooperação".

Estas reflexões ampliam a atenção para a necessidade da existência de competência docente direcionada para as características específicas da $\mathrm{EaD}$, que os prepare para a inovação tecnológica e seus formatos e consequências pedagógicas. Belloni (2006) alerta que a formação de docentes específicos, ou com competências para atuar na EaD, é a chave principal na implementação desta modalidade. Esta mudança é muito mais complexa e ampla do que parece, exige a compreensão pedagógica do processo de aprendizagem como um todo, demanda o desenvolvimento de competências especiais dos docentes e, também, dos discentes.

A modalidade educacional a distância exige que o docente consiga transferir e transformar suas competências para o virtual. Portanto, os docentes atuantes nesta modalidade precisam estar preparados para essa realidade de mudanças. Devido ao contexto específico, onde o discente também é diferenciado, é exigido aos docentes competências distintas, ou seja, estas devem estar adequadas às necessidades e realidade da modalidade.

Em suma, é com este cenário que surgem as discussões sobre o aprimoramento das competências docentes e suas contribuições no processo de ensinoaprendizagem. Percebe-se que existe a busca pela capacitação específica do sujeito como forma de adaptação aos diferentes contextos. Ou seja, o sujeito adapta-se ao ambiente, com suas propriedades, e transforma, modifica e constrói conforme suas competências.

Dito isto, esta pesquisa, limitando-se ao contexto Instituição de Ensino Superior (IES) pesquisada, busca apontar quais competências técnicas e comportamentais podem ser aprimoradas pelos docentes da modalidade de educação a distância (EaD).

\section{Revisão da literatura}

Para que seja realizado um trabalho cientifico, é necessário que o pesquisador obtenha o máximo de informações e conhecimento possível sobre o assunto que é de interesseinvestigar. Tomanik (1994) já afirmava que a fundamentação teórica é o ponto inicial para o autor buscar, a partir das ideias de outros pensadores, colocações importantes para a consolidação de suas ideias centrais e assim dar continuidade ao projeto de forma embasada.

\section{Educação a distância - relevância e definições}

A definição de educação a distância, segundo Moore e Kearsley (2013, p.2), é basicamente: “o aprendizado planejado que ocorre normalmente em um lugar diferente do ensino, o que requer comunicação por meio de tecnologias e uma organização institucional especial”. Segundo Litwin (2001), a EaD busca, simultaneamente, desenvolver o processo educacional e o uso de tecnologias.

A EaD caminha na direção de ser uma modalidade regular e necessária aos sistemas educacionais, estabelecida com uma função de grande importância para atender demandas específicas, demandas da população e demandas de formação, tanto no nível básico, técnico ou superior (VIANNEY; BARCIA; LUZ, 2006). De acordo com Simonson (2006), existem cinco elementos principais na formação da educação a distância:

a) Separação quase permanente do professor e aluno;

b) Influência de uma organização nos processos administrativos;

c) Utilização de meios técnicos para interatividade dos agentes;

d) Comunicação bidirecional;

e) Ensinamentos, na maioria do tempo, individualizados.

Estes elementos citados por Simonson (2006) refletem a essência da modalidade, onde os agentes separados 
fisicamente necessitam de um intermediador, no caso a tecnologia de informação e comunicação (TIC), para o exercício da interação entre estes agentes.

De um modo geral, na EaD a comunicação entre os agentes envolvidos na modalidade está cada vez mais facilitada e os estudantes tem uma flexibilização de tempo de acordo com suas prioridades e necessidades. Portanto, a interatividade mostra-se um dos alicerces relevantes na concepção da modalidade educacional. Essa ligação entre os agentes é um ponto fundamental e deve atender as necessidades dos discentes e do processo de aprendizagem, buscando solucionar e sanar questões tanto teóricas quanto práticas, para o melhor aproveitamento e absorção dos conhecimentos adquiridos ao longo do processo educacional (LENGLER, 2014).

Claramente a modalidade de EaD é uma alternativa viável para ampliar a velocidade e quantidade de atendimento na educação, desde a educação básica até a superior, com o intermédio da tecnologia inerente à modalidade (MOORE; KEARSLEY, 2013). No entanto, o Brasil tem como dois principais desafios, a interiorização e democratização do ensino superior, já que possui, com suas peculiaridades regionais, uma densidade demográfica e dimensões continentais diferenciadas (PENTERICH, 2009).

Entretanto, segundo Litwin (2001), a EaD não é apenas caracterizada pela distância dos agentes, mas também pelas relações via recursos tecnológicos. Através das tecnologias envolvidas na modalidade $\mathrm{EaD}$ existe a possibilidade de realização de encontros, cada vez mais efetivos, por meio da virtualização. Esta modalidade, mediada por tecnologias computacionais, como a internet, apresenta uma nova interface educacional, que transforma o ensino em um compartilhamento de aprendizagens e expurgando a característica, existente na modalidade tradicional de ensino, de autoridade do professor (MAIA, 2003).

Com o desenvolvimento das tecnologias, foram geradas novas formas de aproximação entre os agentes, docentes com discentes e discentes com discentes, evoluindo acerca da interatividade, que é uma das principais características em evolução da modalidade EaD. Desta forma, diversos recursos ou ferramentas tecnológicas de aprendizagem são utilizadas em prol da EaD (LITWIN, 2001).
Neste caso, basicamente, o conceito de interação envolve a ação recíproca entre os agentes atuantes, podendo ser direta ou indireta. A interação, no caso da $\mathrm{EaD}$, tende a ser indireta, pois é dependente da utilização de alguma tecnologia ou ambiente virtual. Normalmente, essa interatividade está ligada a um sistema na internet cuja ferramentas e estratégicas são construídas com o intuito de propiciar um processo de qualidade na aprendizagem e incentivando o trabalho cooperativo (MACHADO, 2009)

Com o entendimento de um dos conceitos principais da $\mathrm{EaD}$, separação física entre docentes e discentes, faz-se necessária uma atuação de gestão por parte da instituiçãoofertantedos cursos, com odesenvolvimento de características específicas nos envolvidos com a modalidade educacional a distância, principalmente em relação ao planejamento, sistematização e projeto organizacional, para ter ganhos efetivos de qualidade nos propósitos educacionais, na transmissão de conhecimento entre professor e aluno (KEEGAN, 1996).

Baseado em conhecimentos gerais, pode-se avaliar que a educação na modalidade a distância é tão complexa quanto a modalidade presencial. Sobre esta distinção das modalidades, segundo os autores Konrath, Tarouco e Behar (2009), a modalidade EaD não é simplesmente uma nova forma de exercer com outra estrutura a pedagogia tradicional da modalidade presencial, pelo contrário, representa mudanças na postura de todos os profissionais envolvidos, com ações de planejamento de ensino e aprendizagem, além de preparação para mudanças inesperadas nos processos que ainda apresentam evolução.

Com isso, a mediação do processo ensinoaprendizagem fica sob responsabilidade dos docentes e apoio efetivo dos tutores que, entre suas funções características, precisam organizar materiais didáticos e de apoio, orientar discentes, responder dúvidas, operacionalizar o ambiente virtual, comentar e corrigir produções, além de interagir nas ferramentas de ensino (KONRATH; TAROUCO; BEHAR, 2009).

Então, a estrutura que envolve toda a modalidade educacional a distância precisa das ações educativas e de comunicação por parte dos envolvidos, gerando trocas ativas e criativas de aprendizagem, adequadamente trabalhadas pelos docentes e desencadeadas pelos discentes e pesquisadores. 
Alguns autores, da área de educação, psicologia e administração demonstram que ainda existe uma dificuldade em relação ao medo de utilizar mecanismos novos. A utilização da tecnologia no ensino reflete uma destas dificuldades, já que a cultura criada na modalidade de ensino presencial é o meio mais tradicional (SANCHO, 1998).

Em partes, o ensino presencial difere da modalidade a distância, onde esta segunda requer necessariamente, devido ao distanciamento existente, uma autonomia de estudos por parte dos discentes. Para que esta característica não prejudique o desempenho do processo de ensino-aprendizagem, por isso, é importante que exista um apoio adequado por parte dos atores da modalidade $\mathrm{EaD}$, principalmente com interação e integração dos envolvidos.

\section{Competências docentes - relevância e definições}

Apesar de o conceito de competência não ser novidade, existem diversos tipos de conceitos, implicações e até mesmo entendimentos distintos que causam muitas divergências em relação a sua compreensão e aplicabilidade. Segundo Resende (2003), o conceito de competência indiretamente está atrelado a uma forma de identificar, a partir de processos seletivos, atributos em indivíduos que exerceriam atividades relacionadas a diversos aspectos, principalmente voltados às esferas organizacionais.

Segundo Perrenoud (1999), competência é a utilização simultânea de recursos cognitivos que auxiliem na resolução de situações que necessitem de saberes, capacidades ou tomadas de decisões. São determinadas pelos contextos que os indivíduos estão inseridos e condições estabelecidas. Moretto (2002) corrobora com os outros autores e resume, competências como analisar, julgar, compreender, relacionar e manipular informações para identificar situações e problemas.

Zarifian (2001) apresenta diferentes interpretações sobre competências, de uma forma mais ampla, que evidenciam aspectos comuns, entre elas: tomar a iniciativa e assumir responsabilidades diante de situações profissionais adversas. Afirma também que o exercício da competência não é possível sem uma base de conhecimentos, mas que somente conhecimento não garante a efetividade da competência, então, é necessário também que ocorra um exercício reflexivo a fim que sejam utilizadas as aprendizagens em favor das tomadas de decisões.

De acordo com Resende (2003), competência é a existência de um conjunto de aplicabilidades, todas ou a parte necessária, são utilizadas será considerada competente.

Competência é a transformação de conhecimentos, aptidões, habilidades, interesse, vontade, etc. em resultados práticos. Ter conhecimento e experiência e não saber aplicá-los em favor de um objetivo, de uma necessidade, de um compromisso, significa não ser competente (RESENDE, 2003, p. 32).

Corroborando com os autores anteriormente citados, para Rabaglio (2004), a competência é formada pelo CHA: conhecimento, habilidade e atitude. O conhecimento é o saber, o que se sabe mas não necessariamente se coloca em prática, a habilidade é o saber fazer, o que se pratica, se tem experiência e domínio sobre a execução, e a atitude é o querer fazer, as características pessoais que levam a praticar ou não o que se conhece e se sabe.

Leme (2005), que mantém a mesma conceituação dos outros autores, define competência como a soma de competências técnicas e competências comportamentais. O autor agrupa, conforme quadro a seguir, portanto, conhecimento e habilidade (o saber e o saber fazer) como competências técnicas, que ao ser trabalhado em conjunto com as competências comportamentais (o querer fazer) vai se transformar em competência. Conforme quadro 1 a seguir:

\section{Quadro 1: Competências Técnicas e Comportamentais}

\begin{tabular}{|c|c|c|c|}
\hline C & Conhecimento & Saber & \multirow{2}{*}{$\begin{array}{c}\text { Competência } \\
\text { Técnica }\end{array}$} \\
\hline H & Habilidade & Saber Fazer & \\
\hline A & Atitude & Querer Fazer & $\begin{array}{c}\text { Competência } \\
\text { Comportamental }\end{array}$ \\
\hline
\end{tabular}

Fonte: adaptado de Leme (2005, p. 18) 
Fleury e Fleury (2004, p. 31) tem uma definição similar, e uma das mais trabalhadas, quando entende competência como o conjunto de competências técnicas e de competências pessoais ou comportamentais. Estratificam-nas pelos saberes mais aprofundadamente:

a) Saber agir: saber o que e por que faz; saber julgar, escolher e decidir;

b) Saber mobilizar: saber mobilizar recursos de pessoas, financeiros, materiais;

c) Saber comunicar: compreender, processar, transmitir informações e conhecimentos;

d) Saber aprender: trabalhar o conhecimento e a experiência;

e) Saber comprometer-se: saber comprometer-se com os objetivos da organização;

f) Saber assumir responsabilidades: ser responsável, assumindo os riscos de ações.

g) Ter visão estratégica: conhecer e entender o negócio, identificando alternativas;

Historicamente, a atividade docente, que focou essencialmente o ensino presencial, considera o relacionamento entre docentes e discentes um fator relevante no processo de construção e disseminação do conhecimento. Vergara (2007) argumenta que existe integração, mesmo que de maneira diferenciada, entre discente e docente na modalidade de EaD. Este relacionamento ainda é mais complexo e abrangente, envolvendo professores, discentes, tutores, monitores e diversas outras pessoas envolvidas nos processos.

Diante de um contexto em que as tecnologias na educação são invariáveis, nota-se que o processo de transformação cultural, imposto pela inserção destas tecnologias, implicam diretamente no cotidiano de todos os envolvidos na modalidade educacional $\mathrm{EaD}$, inclusive nos docentes (CATAPAN, 2001). Para esta autora, neste contexto tecnológico, o docente está sendo desafiado, já que agora aquele conhecimento que, anteriormente, era centrado no saber do docente, ou em livros didáticos, passa a ser compartilhado e construídos coletivamente com intermédio das tecnologias de informação e comunicação (TICs).

De acordo com Catapan (2001, p. 5), a maneira como a mediação do processo ensino-aprendizagem é desempenhada com a inserção das tecnologias o papel do docente neste contexto de ensino é de: "atuar como suporte do processo do qual o aluno é o sujeito, agindo quando há uma demanda consciente por parte do aluno, ou quando percebe que é o momento adequado para um suporte teórico". Para a autora, o desafio está em descobrir quais as possibilidades de interação que ocorrem na relação entre docente, discente e conhecimento, sendo assim, mediadas pela tecnologia de comunicação.

Segundo Belloni (2006), na EaD, o docente interage com os discentes para construir o processo de conhecimento, deixando de ser uma entidade individual para se tornar uma entidade coletiva, ampliando seu foco para um processo de aprendizagem e não mais, apenas, ensino. Por isso, a autora, preocupa-se com a necessidade dos profissionais serem competentes para a realidade da modalidade e para a inovação tecnológica que envolve este modelo de integração e aprendizagem.

Masetto (apud REZENDE, 2004, p. 100-101) aponta que os docentes que desejam atuar na modalidade $\mathrm{EaD}$ precisam desenvolver competências que englobem as seguintes características:

a) Compreender que a aprendizagem é o foco de sua ação educativa;

b) Ser capaz de construir uma relação aluno-professor;

c) Construir uma relação de parceria com o aluno durante toda sua ação educativa;

d) Enfatizar as estratégias cooperativas de aprendizagem;

e) Ter um domínio profundo de sua área de conhecimento;

f) Ser criativo e saber envolver os discentes em soluções novas e crítica; 
g) Estar aberto ao diálogo a qualquer momento e lugar, sendo ágil em dar feedback;

h) Saber desenvolver uma comunicação interpessoal que considere a subjetividade e individualidade dos discentes; e

i) Saber construir uma comunicação que propicie a aprendizagem a distância.

Guimarães (2004), em reflexão aos saberes profissionais docentes, afirma que, como base dos conhecimentos da profissão docente, é necessário subdividir os saberes práticos em saberes pedagógicos-didáticos e saberes relacionados à cultura profissional. Os saberes pedagógico-didáticos referem-se a conhecimentos específicos do processo ensino-aprendizagem e os saberes relacionados à cultura profissional referem-se à explicitação e ao compartilhamento, no processo de formação inicial, do ofício docente como profissão.

Em referência, Masetto (2003) entende que as próprias instituições de ensino, preocupadas com a valorização dos docentes deveriam proporcionarlhes um desenvolvimento das competências básicas necessária. Para o autor, as competências básicas necessárias para a atuação de um docente de ensino superior seriam: competência em determinada área do conhecimento, domínio na área pedagógica e exercício da sua dimensão política.

Entende-se que estas competências básicas são o mínimo necessário para o exercício da atividade docente na modalidade. Entretanto, Pimenta e Anastasiou (2005, p. 82) afirmam que, ao ser indagado sobre o conceito de didática, os docentes de ensino superior, de uma forma geral, com base em suas experiências, dizem que "ter didática é saber ensinar" e "muitos professores sabem a matéria, mas não sabem ensinar". Estas declarações, de certa forma, mostram que os docentes acreditam que a didática lhes fornecerá as técnicas para aplicar em qualquer situação de mediação do ensino e, ao mesmo tempo, evidencia que não basta ter experiência e conhecimentos para conseguir ensinar.

Com a abordagem realizada por Konrath, Tarouco e Behar (2009), que categorizou domínios para as competências mínimas necessárias de cada envolvido no processo educacional a distância, as competências que correspondentes ao exercício docente envolvem os seguintes domínios: cognitivo, técnico, gestão, pedagógico, comunicativo e suporte social.

Esses domínios aparecem distribuídos em todos os momentos de atuação do docente na $\mathrm{EaD}$. As competências técnicas distribuem-se quase que em todos os momentos de sua atuação. As competências comportamentais têm uma variação de atuação mais diversificada, ficando mais constante apenas nos domínios diretamente relacionados à integração.

Cada docente se encontra em uma etapa de desenvolvimento cognitivo e pessoal, por isso, as necessidades de formação de competências não podem ser tomadas como referências isoladas, de modo descontextualizado.

\section{Treinamento e desenvolvimento de docentes}

A capacitação docente para fomentar o processo de ensino-aprendizagem da modalidade de educação não presencial parte do princípio que o ambiente virtual (AVA) existe e da necessidade, devido ao seu contexto dinâmico, de melhores informações sobre os ambientes, das ações vivenciadas com docentes e discentes e a promoção, pelo docente, de experiências de aprendizagem, em salas virtuais, completamente interativas (REZENDE, 2004).

As pesquisas e reflexões de Perrenoud et al (2001) levantam alguns pontos com relação ao desenvolvimento de docentes, onde o primeiro diz respeito ao fato das demandas de formação necessitarem de reforço nos conhecimentos e competências anteriormente adquiridos, o outro ponto é relacionado à demanda por formação e o último ponto é se esta formação realmente responde às necessidades do docente frente à modalidade.

Exercer a atividade profissional docente requer conhecimentos específico. A sociedade contemporânea está em transformação e, segundo Pimenta e Anastasiou (2005), o ensino é um fenômeno multifacetado, que necessita de disseminação e internalização de saberes, conhecimentos, conceitos, habilidade, procedimentos, crenças e atitudes. Nesse sentido, o exercício da docência é compreendido como um ofício pleno de saberes, ou "feito de saberes", 
que são construídos em ações muitas vezes de forma pessoal e experiências adquiridas.

Percebe-se que na formação do docente é necessária experiência profissional, mantendo o que lhe parece válido e possa incorporar a inovação, buscando transformar sua prática de modo significativo ao aprendizado dos discentes. Nos cursos na modalidade $\mathrm{EaD}$, supõe-se necessariamente a autonomia do docente, na busca de novas aprendizagens e na responsabilidade por suas aplicações (REZENDE, 2004).

Competências para atuação docente no ensino não presencial é, talvez, o maior desafio da EaD. De acordo com Sousa (1996), a tecnologia envolvida na modalidade EaD, apesar do custo, pode ser adquirida pelas instituições. A barreira mais significativa está na utilização eficaz desta tecnologia pois necessita a superação dos comportamentos tradicionais de ensino.

Para Rezende (2004), a chave na implementação da modalidade $\mathrm{EaD}$, principalmente no que tange à implementação eficaz, é a formação docente para atuação no processo de aprendizagem a distância. Esta mudança de paradigma é muito mais ampla e complexa do que parece, exige a compreensão pedagógica do processo de ensino-aprendizagem e demanda o desenvolvimento de competências e habilidades específicas dos docentes. Em particular, a educação a distância exige que o docente saiba como transpor sua prática do real para o virtual.

Rezende (2004) afirma que o docente de EaD precisa ter consciência que nesta modalidade educacional, frente aos envolvidos, deverá estar pronto para atuar de forma diferenciada ao tradicional e se posicionando de maneira auxiliar no processo de ensino-aprendizagem, como:

a) Desenvolver o conhecimento pedagógico (teorias de aprendizagem) que o capacite a atuar como instrumento auxiliar de ensino e aprendizagem, usando o computador;

b) Adquirir consistência teórica dos conteúdos disciplinares a serem ensinados; e

c) Aprender, gradativamente, a transpor sua prática do real ao virtual, realizando experiências concretas, dotado de postura reflexiva na e sobre a ação, não aceitando modelos prontos e acabados.

De forma complementar, Pimenta e Anastasiou (2005) aportam que o processo de ensino-aprendizagem não deve ser dado nem assistida, mas construída, feita pela ação conjunta de professores e discentes. O docente, neste cenário, precisa refletir constantemente e coletivamente sobre o que é realizado e, as autoras, atribuem que é essencial considerar a importância da criatividade na solução de cada nova situação vivenciada.

É relevante que os envolvidos, ou agentes de integração da EaD, principalmente os docentes, sejam capacitados e obtenham conhecimento sobre a modalidade. As capacitações para estes envolvidos devem proporcionar maior empatia com os discentes e tutores, assim terão maior propriedade na compreensão das dificuldades encontradas e maior êxito no processo de aprendizagem como um todo (KONRATH; TAROUCO; BEHAR, 2009).

De acordo com Moran (2001), a modalidade EaD já apresentava, na década passada, a realidade de necessitar de políticas de formação de docentes capazes de utilizar a estrutura tecnológica como ferramenta de ensino-aprendizagem, que possibilitasse interação, dialogo e construção de conhecimento, e não apenas a transmissão de informações prontas.

Nesta perspectiva, compreende-se que o formação e desenvolvimento de competências nos docentes da $\mathrm{EaD}$ é relevante que: contemplará a oportunidade de reflexão sobre a teoria e pratica do exercício, possibilitará a evolução do profissional docente atuante que apresente competências e saberes necessários para a pratica da educação mediada por tecnologias e permitirá, por ser uma proposta de formação continuada, que o docente seja o próprio mediador de sua aprendizagem e aprecie um processo de reconstrução da pratica pedagógica na modalidade. 


\section{Metodologia}

De acordo com Araújo e Oliveira (1997), qualquer pesquisa científica pode ser classificada em três modalidades: qualitativa, quantitativa e qualiquantitativa. Basicamente, as pesquisas qualitativas se dedicam à identificação e compreensão de eventos, sem a necessidade de se apoiar em informações estatísticas. As pesquisas quantitativas baseiam-se em dados estatísticos ou matemáticos. As qualiquantitativas apropriam-se de ambas as características.

Esta pesquisa, no momento em que se busca apontar as competências existentes e quais podem ser aprimoradas, apresenta uma abordagem quali-quanti, uma vez que utiliza, em sua coleta e análise de dados, técnicas e ferramentas qualitativas e quantitativas. A pesquisa define-se também como sendo de natureza descritiva, pelo fato de buscar, que de acordo com Gil (2002), apresentar as principais características de um determinado fenômeno e ainda, se possível, estabelecer relações entre variáveis averiguadas.

A pesquisa em questão configura-se também em um estudo de caso, que de acordo com Yin (2005) traz como principais vantagens e características: as novas descobertas e o estímulo para elas, a possibilidade de estudar as variáveis em seu contexto ou ambiente e a simplicidade na aplicabilidade (YIN, 2005). O mesmo autor define o estudo de caso de forma clara e objetiva:

O estudo de caso é uma estratégia utilizada ao se examinarem acontecimentos contemporâneos, mas quando não se podem manipular comportamentos relevantes. [...] e pode-se lidar com uma ampla variedade de evidências documentos, artefatos, entrevistas e observações. [...] em algumas situações, como na observação participante, pode ocorrer manipulação informal (YIN, 2005, p. 26-27).

Desta forma, entende-se que, ao escolher o método estudo, que será a melhor maneira de analisar o objeto de pesquisa permitindo um detalhamento e conhecimento, que faz referência às competências dos docentes atuantes na modalidade EaD da IES pesquisada.

\section{Universo do estudo, sujeitos e coleta e análise de dados}

Para a realização desta pesquisa, delimitou-se como universo de estudo uma Instituição de Ensino Superior (IES) que atua na modalidade a distância em 21 polos presenciais distribuídos nos estados de Santa Catarina (SC), Paraná (PR) e Rio Grande do Sul (RS). A primeira característica utilizada para a escolha dos sujeitos foi a interface com o Curso Superior de Tecnologia (CST) em Processos Gerenciais (TPG), o qual a insituição oferta em todos os polos, e a atuação dos envolvidos com algum processo que possua interação com as atividades dos docentes da modalidade.

Buscou-se entao que todos os respondetes da pesquisa sejam envolvidos com o curso em questão e que possuam interação com os docentes atuantes. A opção pela escolha destes sujeitos foi, principalmente, devido à proximidade e interação que tais atores possuem nas diversas atribuições dos docentes da EaD.

Foram ao todo duas etapas, uma com pesquisas documentais internas com observação direta e outra com um questionário de questões objetivas, disponibilizado via formulário digital. São respondentes do questionário, via formulário digital, os tutores presenciais, gestores dos polos e discentes. Ao todo foram selecionados para esta etapa: cerca de 570 discentes do curso TPG, 12 tutores presenciais do curso TPG e 10 gestores dos polos.

As análises de dados que forma realizadas abordaram: análise interpretativa e análise estatística de dados. $\mathrm{O}$ delineamento da pesquisa é: documental, bibliográfica e estudo de caso. Os instrumentos de coleta serão: questionários com questões de múltipla escolha, documentos, observação direta e bibliografias.

Portanto, a partir das pesquisas documentais, dados secundários oriundos de conversas e pesquisas internas e observação direta na IES, foram levantados os indicativos das competências docentes em EaD, identificado qual o nível requerente de competências e quais são elas e o que já vem sendo traçado na formação destes profissionais para os propósitos da modalidade. Já o questionário de perguntas de múltipla escolha aplicado, tem como objetivo identificar em que nível encontram as competências docentes em cada grupo e dimensão proposta pela pesquisa, de acordo com a percepção dos atores respondentes. 


\section{Categorias de análise}

Assim como os demais autores, o conceito de competência é definido como a soma das competências técnicas e competências comportamentais. Leme (2005), apresentado anteriormente, resume e agrupa os conceitos das competências de diversos autores da área, de acordo com a segmentação de competências técnicas, que englobam o saber e o saber fazer, e competências comportamentais.

Para uma melhor construção do questionário e exploração dos conteúdos informativos, foram consideradas duas dimensões de competências, que são referentes à interação dos docentes com discentes e com os tutores. Cada dimensão a ser analisada diz respeito a um universo de questionamentos voltados para a formação daquele grupo de competências, ou à que se refere, conforme a seguir (BENETTTI, 2008):

a) Interação com discente: Refere-se à interação do docente com os discentes. Isso acontece quando o docente interage com o discente por meio das aulas, videoconferências, seminários e outros momentos virtuais ou presenciais;

b) Interação com tutor: Refere-se à interação do docente com a tutoria. Isso acontece quando o docente interage com os tutores e coordenadores por meio de seminários, treinamentos, soluções de dúvidas e elaboração de avaliações.

Primeiramente, os docentes interagem com os discentes por meio das aulas ao vivo, de chats, videoconferências, plataforma interativa, entre outros meios. O contato dos docentes com os tutores é constante, já que é o tutor que faz o intermédio entre o discente e o docente e, por isso, o alinhamento do entendimento e discurso com o docente é de grande importância. Essas dimensões, apresentadas e explicadas, servem para segmentar as competências e mais facilmente analisá-las junto ao questionário.

Além disso, também foram utilizados, para estratificar as competências, os conceitos de domínios, fundamentados pelos autores Konrath, Tarouco e Behar (2009), que se referem às esferas em que os docentes atuam e aplicam seus conhecimentos, habilidades e atitudes. Estes domínios de competências são: a) Domínio Cognitivo: agrupam as competências que aparecem na forma de atribuição direta da função do docente;

b) Domínio Técnico: referente ao conhecimento e habilidade da utilização das ferramentas e tecnologia;

c) Domínio de Gestão: relacionado diretamente ao papel do docente, atividades relacionadas a organização pedagógica e em nível administrativo do curso;

d) Domínio Pedagógico: referente aos atos pedagógicos, suporte de atividades e principalmente da responsabilidade de acompanhamento do processo de aprendizagem;

e) Domínio Comunicativo: referente a presença de comunicação dos docentes, instigando participação, opinando, informando, estabelecendo discussões e contato e corrigindo;

f) Domínio de Suporte Social: na forma de avaliação dos efeitos sociais e estratégia de promover a solidariedade do grupo envolvido.

Estes domínios tem o intuito de apresentar de forma mais clara e objetiva as segmentações de atividades e efeitos do exercício da função do profissional docente. Com estes domínios, será possível a identificação distinta de estratégias utilizadas para promover os processos da função, alocar atividades relacionadas, apontar conhecimento e habilidade na utilização dos recursos, observar a presença dos meios de comunicação apresentados e, de uma forma direcionada, avaliar quais os requisitos estão sendo estabelecidos e onde eles ocorrem.

Portanto, as categorias de análise são definidas de acordo com as dimensões: interação com discente e interação com tutor. Já as competências docentes estão segmentadas e foram analisadas e trabalhadas separadamente em competências técnicas e competências comportamentais e estratificadas nos domínios: cognitivo, técnico, de gestão, pedagógico, comunicativo e de suporte social. Conforme 


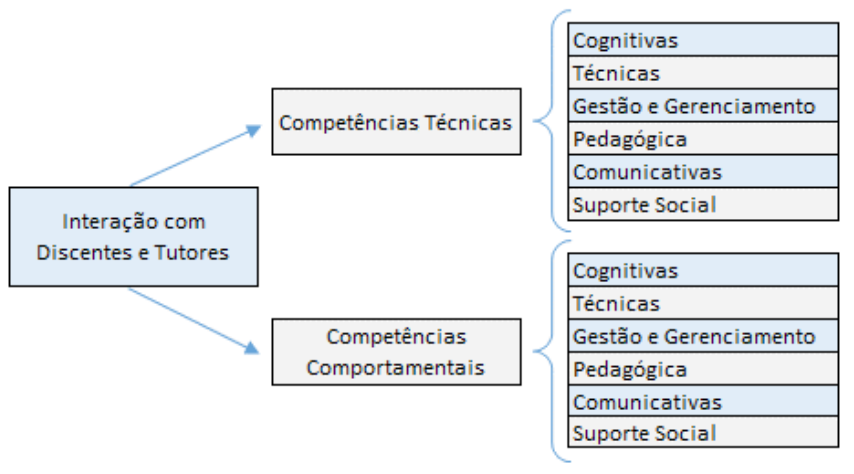

Fonte: Elaborado pelo autor (2015)

Com isso, neste estudo obtém-se, a partir da percepção dos atores da modalidade $\mathrm{EaD}$, que interagem com os docentes, quais as competências docentes para a modalidade $\mathrm{EaD}$ necessitam de aprimoramento. Portanto, o objetivo é elencar cada carência de competência para indicar quais pontos podem ser desenvolvidos ou treinados em cada dimensão, buscando a obtenção de impactos positivos para os cursos EaD da IES.

\section{Limitações da pesquisa}

Como aspectos que determinam até onde será possível alcançar os resultados, os aspectos de limitação desta pesquisa são devido à metodologia utilizada e opções definidas na construção do objetivo principal da mesma.

O primeiro aspecto de limitação se dá devido a esta pesquisa limitar-se ao nível de graduação, utilizando como fonte de informações de apenas um curso superior de tecnologia (CST) ofertados pela IES da modalidade EaD. Entretanto, os resultados podem ser, com seus devidos ajustes, extrapolados para outros cursos e níveis de ensino ou instituições, desde que a pesquisa readequada para tal abrangência.

O segundo aspecto diz respeito às opções definidas nas categorias de análise. Para este trabalho entendese apenas a identificação de lacunas e análise de onde podem ser aprimoradas as competências docentes dos profissionais atuantes na modalidade e atividades da $\mathrm{EaD}$.

Com relação à população e sujeitos da pesquisa, entende-se ser acessível, mas com certa dificuldade de conversão dos questionários, e acredita-se também que o tema principal da pesquisa é de interesse da grande maioria dos participantes, inclusive da IES que poderá aderir de forma integral ou parcial as preposições aqui alcançadas.

\section{Desenvolvimento e resultados}

A fim de buscar atender o objetivo principal desta pesquisa, nesta seção são apresentados os principais componentes e análises aferidas com as pesquisas e questionários aplicados no ambiente pesquisado.

\section{Competências docentes existentes na ead da ies}

As análises a seguir são oriundas do questionário realizado com os Discentes, Tutores e Gestores de Polo, chamados aqui de atores $\mathrm{EaD}$, e suas percepções acerca da concordância ou não da existência de competências docentes. Este questionário de múltipla escolha, teve embasamento de sua criação as pesquisas documentais e observações diretas feitas internamente na IES. De acordo com o levantamento teórico realizado para a pesquisa, foram consolidadas competências considerando as dimensões técnicas e comportamentais subdivididos por esferas de domínios, com foco na interação dos docentes com discentes e com os tutores.

A escala utilizada para mensuração das competências docentes, nesta etapa, foi estabelecida de 1 a 6 , em que o número 1 significa a posição do respondente de "discordo totalmente", o número 2 de "discordo", o número 3 de "discordo pouco", o número 4 de "concordo pouco", o número 5 de "concordo", o número 6 de "concordo totalmente". A partir desta escala, entende-se que a média próxima a 1 representa uma possível falta de competência e a média próxima a 6 representa a presença satisfatória de competência no exercício da atividade relacionada. Por existir a possibilidade do respondente não conhecer e não puder opinar sobre algum questionamento, foi incluída a opção de "desconheço" para todas as perguntas. Os respondentes que assinalaram esta opção foram desconsiderados, para a pergunta em questão, sem prejudicar os cálculos e análises. 
Com o conjunto de competências consolidado, forma de mensuração e sujeitos definidos, foi construído um o instrumento capaz de medir o grau de concordância de existência de cada grupo de competência, representado pelos domínios, os docentes da IES apresentam.

Nesta etapa foram obtividas respostas de 90 atores da modalidade EaD da IES, entre eles: discentes (75), tutores (08) e gestores de polo (07). Pela quantidade absoluta, o volume de discentes é maior, mas por adesão percentual de respondentes, os tutores e gestores aproximaram-se de $75 \%$, ou seja, cerca de $3 / 4$ do total de participantes responderam o questionário enviado, enquanto a adesão de discentes representou cerca de $18 \%$ do total de aptos a participar e responder o questionário.

De acordo com as informações levantadas a partir dos questionários, em relação ao conjunto de competências técnicas, referente aos domínios destacados, os atores respondentes entenderam conforme tabela 1 a seguir:

Tabela 1: Média de Competências Técnicas por Domínio

\begin{tabular}{l|c|c|c}
\multicolumn{1}{c}{\begin{tabular}{c} 
Competências \\
\multicolumn{1}{c}{ Técnicas }
\end{tabular}} & \multicolumn{1}{c}{$\begin{array}{c}\text { Discentes } \\
\text { TPG }\end{array}$} & \multicolumn{1}{c}{$\begin{array}{c}\text { Tutores } \\
\text { Presenciais }\end{array}$} & \multicolumn{1}{c}{$\begin{array}{c}\text { Gestores } \\
\text { de Polos }\end{array}$} \\
\hline Domínio Cognitivo & 4,72 & 5,25 & 4,71 \\
\hline Domínio Técnico & 4,64 & 5 & 4,67 \\
\hline Domínio de Gestão & 4,59 & 4,92 & 4,52 \\
\hline Domínio Pedagógico & 4,26 & 4,5 & 4,39 \\
\hline $\begin{array}{l}\text { Domínio } \\
\text { Comunicativo }\end{array}$ & 4,17 & 4,88 & 4,07 \\
\hline $\begin{array}{l}\text { Domínio de Suporte } \\
\text { Social }\end{array}$ & 4,53 & 4,88 & 4,62 \\
\hline Média Total & 4,49 & 4,9 & 4,5 \\
\hline
\end{tabular}

Fonte: Dados primários (2014)

Para as competências técnicas em geral, nenhuma segmentação ficou abaixo da média 4,0, ou seja, fora da escala de "concordo". A visão dos tutores foi a que apontou médias maiores entre todos os atores respondentes, chegando na média geral em 4,90, enquanto na visão dos discentes foi 4,49 e na visão dos gestores foi 4,50 , esses dois últimos com análise muito próximas em diversos domínios.

Analisando a tabela 1, observou-se que, na avaliação de todos os atores respondentes, com maior média são as competências inseridas no domínio cognitivo, com discentes apontando uma média de 4,72, tutores uma média de 5,25 e gestores uma média de 4,71. Com isso, entende-se que o domínio cognitivo está bem percebido, uma vez que todos os atores, incluindo o grande volume de discentes, avaliaram e atribuíram médias, em média, acima de concordo, aproximandose da média máxima.

Referente ao domínio com a média mais baixa, também com o consenso dos três grupos de atores, destacaramse as competências do domínio comunicativo. No domínio referido, os discentes apontaram uma média de 4,17, os tutores apontaram a média de 4,88 e os gestores a média de 4,07 . Estas percepções dos atores reflete um déficit neste domínio em todas as esferas exploradas pelo questionário.

De uma maneira geral, percebe-se também, a partir da análise das médias obtidas, que os tutores presenciais concordaram em maior número com a existência das competências analisadas no questionário, atribuindo média total de 4,90, enquanto os gestores de polos e discentes tiveram uma similaridade em suas avaliações, com uma percepção inferior atribuindo médias, respectivamente, de 4,50 e 4,49.

Para as competências comportamentais, as médias atribuídas em geral, são inferiores às técnicas, apresentadas anteriormente. Porém, isto pode ser reflexo da subjetividade e da maior complexidade de mensurar estas competências. Em relação ao grupo das competências comportamentais, as médias atribuídas foram dispostas como mostra a tabela 2 a seguir:

Tabela 2: Média de Competências Comportamentais por Domínio

\begin{tabular}{l|c|c|c}
\hline \multicolumn{1}{c}{$\begin{array}{c}\text { Competências } \\
\text { Comportamentais }\end{array}$} & \multicolumn{1}{c}{$\begin{array}{c}\text { Discentes } \\
\text { TPG }\end{array}$} & \multicolumn{1}{c}{$\begin{array}{c}\text { Tutores } \\
\text { Presenciais }\end{array}$} & \multicolumn{1}{c}{$\begin{array}{c}\text { Gestores } \\
\text { de Polos }\end{array}$} \\
\hline Domínio Cognitivo & 4,24 & 4,63 & 4,36 \\
\hline Domínio Técnico & 3,83 & 3,83 & 3,93 \\
\hline Domínio de Gestão & 4,16 & 4,78 & 4,3 \\
\hline Domínio Pedagógico & 4,14 & 4,52 & 4,32 \\
\hline $\begin{array}{l}\text { Domínio } \\
\text { Comunicativo }\end{array}$ & 4,08 & 4,75 & 4,48 \\
\hline $\begin{array}{l}\text { Domínio de Suporte } \\
\text { Social }\end{array}$ & 4,17 & 4,63 & 4,43 \\
\hline Média Total & 4,1 & 4,52 & 4,3 \\
\hline
\end{tabular}

Fonte: Dados primários (2014) 
Observa-se que este grupo de competências apresentou as médias em um nível um pouco inferior. De um modo geral, comparando as médias totais atingidas nos grupos de competências técnicas e competências comportamentais, as médias atribuídas pelos discentes caíram de 4,49 para 4,10, as médias atribuídas pelos tutores caíram de 4,90 para 4,52 e as médias atribuídas pelos gestores caíram de 4,50 para 4,30 .

Nas competências comportamentais, apresentadas na tabela 2, como média total, considerando todos os domínios, os discentes atribuíram 4,10 de média, enquanto os tutores atribuíram 4,52 e os gestores atribuíram 4.30. Então, neste conjunto de competências, os três grupos de atores analisaram no geral aproximadamente a mesma avaliação.

O destaque negativo neste conjunto de competências comportamentais para o domínio técnico, no qual aborda questões acerca do monitoramento de desempenhos e reconhecimento de necessidade e limitações, e apresentou médias abaixo dos 4 pontos, a partir da análise de todos os grupos de atores. Para o domínio técnico, os discentes e os tutores atribuíram 3,83 de média e os gestores atribuíram 3,93 de média. Considerando-se a escala de respostas, estas médias ficam dentro da escala do "discordo", ou seja, a grande maioria dos respondentes não observou tais competências no exercício laboral dos docentes na $\mathrm{EaD}$.

Como destaque positivo, cada grupo de ator apontou um domínio diferente. As melhores médias atribuídas pelos discentes foi para o domínio cognitivo que, apesar de estar próximo da escala dos discordo, apresentou média de 4,24. A maior média atribuída pelos tutores e foi para o domínio de gestão com 4,78 e a sua segunda maior, que ficou muito próximo do domínio de gestão, foi para o domínio comunicativo com 4,75 de média. Para os gestores, também foram atribuídas notas maiores, na média, para o domínio comunicativo com 4,48.

Observa-se, então, para as competências comportamentais, uma similaridade e déficit no que tange às atribuições do domínio técnico. Para os outros domínios, as notas foram atribuídas, de uma forma geral, com maiores médias pelos tutores e gestores, respectivamente, enquanto os discentes atribuíram as menores notas, refletindo a percepção da existência de competências por estes atores.

\section{Detalhamento das competências a serem aprimoradas}

Com o detalhamento dos dados pesquisados e apresentados anteriormente, percebe-se que no âmbito das competências docentes existe margem para aprimoramentos. Nesta etapa foram consolidadas e segmentadas, de acordo com os critérios pesquisados, quais e onde podem ser estes melhoramentos.

De acordo com a escala utilizada no questionário de múltipla escolha, as médias atribuídas entre 4,00 e 5,00 podem ser consideradas normais, ou seja, atendendo as necessidades atuais da IES, mas para efeito de análise, as médias que estiverem próximas de 4,00 serão avaliadas como pontos de atenção e a desenvolver.

Considerando os atores respondentes com o mesmo peso e grau de importância, na mensuração das médias gerais, pôde-se observar alguns domínios com resultado piores, aproximando da média 4,00. Representados na tabela 3, são eles:

Tabela 3: Média geral de competências por domínios

\begin{tabular}{l|c|c}
\hline & \multicolumn{1}{c}{$\begin{array}{c}\text { Competências } \\
\text { Técnicas }\end{array}$} & $\begin{array}{c}\text { Competências } \\
\text { Comportamentais }\end{array}$ \\
\hline Domínio Cognitivo & 4,89 & 4,41 \\
\hline Domínio Técnico & 4,77 & 3,87 \\
\hline Domínio de Gestão & 4,68 & 4,41 \\
\hline Domínio Pedagógico & 4,38 & 4,33 \\
\hline $\begin{array}{l}\text { Domínio } \\
\text { Comunicativo }\end{array}$ & 4,37 & 4,44 \\
\hline $\begin{array}{l}\text { Domínio de Suporte } \\
\text { Social }\end{array}$ & 4,68 & 4,41 \\
\hline Média Total & 4,63 & 4,31 \\
\hline
\end{tabular}

Fonte: Dados primários (2014) 
Dentre as competências técnicas, os domínios pedagógico e comunicativo mostram um ponto de atenção, no que se refere ao atendimento das competências pela percepção dos atores respondentes. No domínio pedagógico, o tema principal abordado no questionário foi acerca das atividades pedagógicas utilizadas, técnicas de facilitam a aprendizagem e suporte ao processo de aquisição de conhecimento. No domínio comunicativo, os questionamentos permearam a transmissão de conhecimento de forma clara o objetiva e a capacidade de construir contato a distância. De acordo com Masetto (apud REZENDE, 2004), os docentes precisam compreender que a aprendizagem é o foco principal de seu exercício, mas o domínio das estratégias pedagógicas e da construção de uma comunicação, que possa propiciar a aprendizagem, são essenciais para o processo como um todo.

Dentre as competências comportamentais, as menores médias apresentadas formam nos domínios técnico e pedagógico. O domínio técnico, no âmbito comportamental, abordava utilizar os recursos para acompanhar e monitorar o desempenho dos atores e, através disto, reconhecer limitações e aspirações os mesmos. Já no domínio pedagógico, as questões trouxeram o enfoque da existência de acompanhamento e cooperação do processo evolutivo dos discentes, transmissão de novos conhecimentos e ensinamentos, estimulo e envolvimento dos participantes e promover a autorreflexão. O autor Guimarães (2004) corrobora mencionando que é necessário que o docente subdivida os saberes práticos dos saberes pedagógicos, uma vez que o conhecimento deve ser compartilhado com a melhor metodologia.

Com tudo o que foi apresentado, foram levantadas informações que servem agora de fomento para tomadas de decisão dentro da IES. As primeiras observações acerca de melhorias tomaram-se evidentes nas pesquisas documentais e observações diretas e depois foram consideradas e analisadas frente ao avaliado pelos participantes respondentes dos questionários aplicados. A partir destas frentes e observações, pôde-se levantar a potencialidade de melhoria nos seguintes quesitos:

a) Ações pedagógicas: moldar estratégias voltadas para o perfil predominante dos discentes do curso; b) Qualificação: necessidade de preparação para o monitoramento das atividades oferecidas, acompanhamento da evolução de aprendizagem e definição da utilização do ambiente virtual de aprendizagem (AVA) e as técnicas para utilização do sistema;

c) Capacitação: direcionamentos para atividades virtuais, como em estúdio, voz, postura, olhar, etc.;

d) Processos: capacidade e autonomia de resolução de problemas;

e) Treinamentos: explorar o AVA e suas ferramentas, para utilização e preparação de atividades e materiais;

f) Competências Técnicas: questões relacionadas ao domínio pedagógico e domínio comunicativo;

g) Competências Comportamentais: questões relacionadas ao domínio técnico e domínio pedagógico.

Portanto, observou-se os pontos que podem ser explorados e analisados para as futuras melhorias nos processos, aprimoramentos e desenvolvimento da IES, as análises realizadas apontaram a necessidade de examinar as características que tangem as competências técnicas, principalmente com os processos internos e utilização dos sistemas e ferramentas da IES, e as competências comportamentais, principalmente pontos voltados para o processo de ensinoaprendizagem, envolvimento com o discentes e monitoramento e motivação das atividades delegadas em propósito da realização da aprendizagem.

\section{Considerações finais}

Evidentemente que a modalidade EaD passa por um momento de consolidação e crescimento no país. Essa expansão está acontecendo em diversos níveis e instituições, sejam elas particulares, estaduais ou federais. Mas para que os resultados deste crescimento seja positivo, as ações devem ser feitas observando referenciais e características de qualidade, para que 
assim haja um aumento qualitativo e não apenas meramente quantitativo.

Para que tal expectativa de qualidade seja apreciada juntamente com o crescimento da modalidade é de relevante importância o entendimento dos papeis e objetivos acerca do projeto da $\mathrm{EaD}$ em cada instituição e dos envolvidos nele. Contudo, especificamente na IES pesquisada, para que este crescimento sustentado seja alcançado, se faz necessário identificar as melhores maneiras de atuação de todos envolvidos, principalmente do docente atuante na $\mathrm{EaD}$, e com esse cenário de evolução e baixo conhecimento é preciso entender em que medida se dão estas exigências e medir o nível de competências atendidas na execução das funções determinadas.

Objetivando o alcance do objetivo geral da pesquisa, além de pesquisas bibliográficas para o entendimento do contexto explorado, pesquisas documentais e observação direta, foi elaborado e aplicado um questionário com questões de múltipla escolha, que captavam o grau de concordância na existência de competências específicas.

Considerando as categorias de análise elaboradas e o que já foi estratificado neste trabalho, para a obtenção do atendimento dos objetivos da pesquisa, todas as competências foram medidas e classificadas com notas que variam entre 1,00 e 6,00, onde também pode ser gerada uma escada de discordância, entre 1,00 a 3,99, e concordância, entre 4,00 a 6,00, mas a principal leitura destas médias atribuídas pelos atores foi feita em sua resposta descritiva, apontando e interpretando o nível de concordância da existência de cada uma.

Em relação as competências medidas, pode-se verificar que, de uma forma geral, todos os domínios tiveram uma similaridade por grupo de competência. Conforme a tabela 6 a seguir:
Tabela 4: Média geral das competências por domínios

\begin{tabular}{|c|c|c|c|c|c|c|c|}
\hline & 芑 & 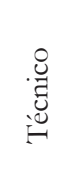 & 胥 & 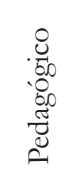 & 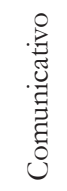 & 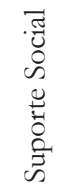 & 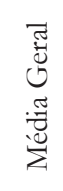 \\
\hline $\begin{array}{l}\text { Competências } \\
\text { Técnicas }\end{array}$ & 4,89 & 4,77 & 4,68 & 4,38 & 4,37 & 4,68 & 4,63 \\
\hline $\begin{array}{l}\text { Competências } \\
\text { Comportamentais }\end{array}$ & 4,41 & 3,87 & 4,41 & 4,33 & 4,44 & 4,41 & 4,31 \\
\hline
\end{tabular}

Fonte: Dados primários (2014)

Nas competências técnicas, a média geral foi muito próxima do indicador que fica entre as opções de "concordo" e "concordo totalmente". Neste grupo, alguns domínios obtiveram percepções melhores e outros piores, mas todos ficaram aproximadamente em torno da média geral. Os domínios com resultados de pico, foram: Cognitivo e Técnico. Os domínios com resultados de vale, foram: Pedagógico e Comunicativo.

Nas competências comportamentais, as médias atribuídas por domínios também seguiram a mesma lógica, com a maioria ficando com média entre as opções de "concordo" e "concordo totalmente". Apenas um domínio acabou apresentando a média inferior, o domínio técnico que se enquadra entre as opções de "concordo pouco" e "concordo". Já o domínio com melhor atribuição de média e percepção dos atores foi o comunicativo, próximo da média geral.

Portanto, a partir dos resultados obtidos em cada etapa da pesquisa, verifica-se que, para o atendimento do objetivo principal, algumas competências docentes podem ser aprimoradas para a consolidação e aperfeiçoamento da modalidade a distância na IES. As competências requeridas pela instituição estão relacionadas com as pesquisadas e apresentadas pelos docentes atuantes, entretanto, existe uma margem alcançável para o aprimoramento da maioria delas.

Sa limitações da competências apresentadas foram pouco significativas, entretanto, uma observação mais aprofundada remete à necessidade e potencial de melhoramentos, nos dois grupos de competências e em domínios específicos. Tais aprimoramentos, 
podem ser trabalhados em forma de desenvolvimento de programas relacionados à capacitação profissional com metodologias práticas que simulem e gerem experiências específicas para a modalidade educacional.

Assim como no contexto da IES pesquisada, outras instituições podem adaptar a pesquisa e métodos utilizados para realidades distintas, desde que considerando as especificidades de cada cenário proposto. Como proposta de novos estudos, mostra-se importante a inclusão e apontamentos dos treinamentos e capacitações propícios para o desenvolvimento de tais competências e donmínios, abordagem que não fora foco desta pesquisa.

\section{Referências}

ARAÚJO, A. O; OLIVEIRA, M. C. Tipos de pesquisa. Trabalho de conclusão da disciplina Metodologia de Pesquisa Aplicada a Contabilidade Departamento de Controladoria e Contabilidade da USP. São Paulo, 1997.

BARRETO, E. S. S; PINTO, R. P; MARTINS, A. M. Formação de docentes a distância: reflexões sobre um programa. Cadernos de Pesquisa, n.106, p.81115, março/1999. Disponível em: < http://www. scielo.br/pdf/cp/n106/n106a04.pdf >. Acesso em: 01 mar. 2014.

BELLONI, M. L. Educação a distância. 4. ed, Campinas: Autores Associados, 2006.

BENETTI, K. C. Competências docentes para ead: análise da realidade do curso de graduação em administração a distância da Universidade Federal de Santa Catarina. 2008. 111 f. Dissertação (Mestrado em Administração) - Programa de PósGraduação em Administração. Universidade Federal de Santa Catarina, Florianópolis. 2008.

CATAPAN, A. H. TERTIUM: o novo modo do ser, do saber e do apreender (construindo uma taxionomia para mediação pedagógica em tecnologia de comunicação digital). 2001. 289 f. Tese (Doutorado em Engenharia de Produção) - Programa de Pós-graduação em Engenharia de Produção. Universidade Federal de Santa Catarina, Florianópolis. 2001.
FLEURY, A; FLEURY, M. T. L. Estratégias empresariais e formação de competências: um quebra-cabeça caleidoscópico da indústria brasileira. 3. ed. São Paulo: Atlas, 2004.

GIL, A. C. Como elaborar projetos de pesquisa. 4. ed. São Paulo: Atlas, 2002.

GUimarães, V. S. Formação de Professores: saberes, identidade e profissão. 3. ed. Campinas, Papirus, 2004.

\section{KEEGAN, D. Foundations of Distance}

Education. Londres: Routledge, 1996.

\section{KLAES, L. S. Cooperativismo e ensino a} distância. 2005. 270 f. Tese (Doutorado em Engenharia de Produção) - Programa de PósGraduação em Engenharia de Produção. Universidade Federal de Santa Catarina, Florianópolis, 2005.

KONRATH, M. L. P.; TAROUCO, L. M. R.; BEHAR, P. A. Competências: desafios para alunos, tutores e professores da EaD. Porto Alegre: CINTED-UFRGS, v.7, n.1, julho, 2009.,

LEME, R. Aplicação prática de gestão de pessoas por competências: mapeamento, treinamento, seleção, avaliação e mensuração de resultados de treinamento. Rio de Janeiro: Qualitymark, 2005.

\section{LENGLER, F. R. Competências docentes na} educação a distância: estudo de caso no curso de tecnologio em processos gerenciais. 2014. 184 folhas. Dissertação (Mestrado Profissional em Administração Universitária) - Programa de PósGraduação em Administração. Universidade Federal de Santa Catarina, Florianópolis, 2014.

LITWIN, E. Das tradições à virtualidade. In: Litwin, Edith (Org.). Educação a distância: temas para o debate de uma nova agenda educativa. Porto Alegre: Artmed, p. 13-22, 2001.

\section{MACHADO, S. A. As ferramentas de} comunicação em educação a distância: estudo de caso do portal educação. Estudo de caso em uma empresa de educação a distância. Dissertação (Mestrado em Organizações e Desenvolvimento) FAE Centro Universitário. Curitiba, 2009. 
MAIA, M. C. O uso da tecnologia de informação para a Educação a Distância no Ensino

Superior. 2003. Tese (Doutorado em Administração de Empresas) - Escola de Administração de

Empresas de São Paulo da Fundação Getúlio Vargas, São Paulo, 2003.

MASETTO, M. T. Competência pedagógica do professor universitário. São Paulo: Summus, 2003.

MOORE, M.; KEARSLEY, G. Educação a distância: uma visão integrada. Edição Especial da Associação Brasileira de Educação a Distância. São Paulo: Thomson Learning, 2013.

MORAES, M. C. Tecendo a rede, mas com que paradigma? In: MORAES, M. C. (Org.). Educação a distância: fundamentos e práticas. Campinas: UNICAMP/NIED, 2002.

MORAN, J. M. (Org.). Novas tecnologias e medição pedagógicas. Campinas. São Paulo: Papirus, 2001.

MORETTTO, V. P. Construtivismo, a produção do conhecimento em aula. 3.ed. Rio de Janeiro: DP\&A, 2002.

NOTARE, M. R; BEHAR, P. A. A comunicação matemática on-line por meio de ROODA Exata. In: BEHAR, P. A. (Org.). Modelos pedagógicos em Educação a Distância. Porto Alegre: Artmed, 2009.

PENTERICH, E. Competências organizacionais para oferta de educação a distância no ensino superior: um estudo descritivo exploratório de IES brasileiras credenciadas pelo MEC. São Paulo: USP, 2009. 260f.

PERRENOUD, P. Construir as competências desde a escola. Porto Alegre: Artmed, 1999.

PERRENOUD, P; et al. (Orgs.). Formando professores profissionais: quais estratégias? quais competências? 2. ed. Porto Alegre: Artmed, 2001.

PIAGET, J; GRECO, P. Aprendizagem e conhecimento. São Paulo: Freitas Bastos, 1974.

PIMENTA, S. G; ANASTASIOU, L. G. C. Docência no ensino superior. 2. ed. São Paulo: Cortez, 2005.
RABAGLIO, M. O. Ferramentas de avaliação de performance com foco em competências. Rio de Janeiro: Qualitymark, 2004.

RESENDE, E. O livro das competências: desenvolvimento das competências: a melhor autoajuda para pessoas, organizações e sociedade. 2. ed. Rio de Janeiro: Qualitymark, 2003.

REZENDE, F. A. Características do ambiente virtual construcionista de ensino e aprendizagem na formação de professores universitários. 2004. 246f. Dissertação (Mestrado em Multimeios) - Instituto de Artes. Universidade Estadual de Campinas, Campinas, 2004.

SANCHO, J. M. (Org.). Para uma Tecnologia

Educacional. Porto Alegre: Artes, 1998.

SIMONSON, M. In: BARBERÀ, E. (Org.).

Educación abierta y a distancia. Barcelona: UOC, 2006.

SOUSA, E. C. B. M. Panorama internacional da educação a distância. Brasília, n.70, abr-jun. 1996.

TOMANIK, E. A. O olhar no espelho: "conversas" sobre a pesquisa em ciências sociais. Maringá: EDUEM, 1994.p. 133-139.

VERGARA, S. C. Estreitando relacionamentos na educação a distância. Cadernos EBAPE.BR. Edição especial PDCA 2007.

VIANNEY, J.; BARCIA, R. M.; LUZ, R. J. P. Universidade Virtual: oportunidade de crescimento ou ameaça para as instituições de ensino superior? Revista Estudos. n. 26. ago. 2006. Disponível em: <http://www.abmes.org.br/abmes/publicacao/ detalhe/id/14> Acesso em: 01 mar. 2014.

YIN, R. K. Estudo de caso: planejamento e métodos. Porto Alegre: Ed. Bookman, 2010.

ZARIFIAN, P. Objetivo competência: por uma nova lógica. São Paulo: Atlas, 2001. 